\title{
Comparative PL study of individual ZnO nanorods, grown by APMOCVD and CBD techniques
}

\author{
Volodymyr Khranovskyy, Rositsa Yakimova, Fredrik Karlsson, Abdul S Syed, Per-Olof \\ Holtz, Zelalem Nigussa Urgessa, Oluwatobi Samuel Oluwafemi and \\ Johannes Reinhardt Botha
}

\section{Linköping University Post Print}

N.B.: When citing this work, cite the original article.

Original Publication:

Volodymyr Khranovskyy, Rositsa Yakimova, Fredrik Karlsson, Abdul S Syed, Per-Olof Holtz, Zelalem Nigussa Urgessa, Oluwatobi Samuel Oluwafemi and Johannes Reinhardt Botha, Comparative PL study of individual $\mathrm{ZnO}$ nanorods, grown by APMOCVD and CBD techniques, 2012, Physica. B, Condensed matter, (407), 10, 1538-1542.

http://dx.doi.org/10.1016/j.physb.2011.09.080

Copyright: Elsevier http://www.elsevier.com/

Postprint available at: Linköping University Electronic Press http://urn.kb.se/resolve?urn=urn:nbn:se:liu:diva-77525 


\title{
Comparative PL study of individual $\mathrm{ZnO}$ nanorods, grown by APMOCVD and CBD techniques
}

\author{
Volodymyr Khranovskyy ${ }^{1}$, , Rositza Yakimova ${ }^{1}$, Fredrik Karlsson ${ }^{1}$, Abdul S. Syed ${ }^{1}$, Per- \\ Olof Holtz ${ }^{1}$, Zelalem Nigussa Urgessa ${ }^{2}$, Oluwatobi Samuel Oluwafemi ${ }^{3}$, Johannes Reinhardt \\ Botha $^{2}$ \\ ${ }^{1}$ Department of Physics, Chemistry and Biology (IFM), Linköping University, 58183 \\ Linköping, Sweden \\ ${ }^{2}$ Department of Physics, P.O Box 77000, Nelson Mandela Metropolitan University, Port \\ Elizabeth, 6031, South Africa \\ ${ }^{3}$ Department of Chemistry and Chemical Technology, Walter Sisulu University, Mthatha \\ Campus, Private Bag XI, 5117, South Africa \\ *Corresponding author. \\ e-mail address: volkh@ifm.liu.se \\ tel: +46-13-282663 \\ fax: $+46-13-137568$
}

\begin{abstract}
The photoluminescence properties of individual $\mathrm{ZnO}$ nanorods, grown by atmospheric pressure metalorganic chemical vapor deposition (APMOCV) and chemical bath deposition (CBD) are investigated by means of temperature dependent micro-PL. It was found that the low temperature PL spectra are driven by neutral donor bound exciton emission $\mathrm{D}^{0} \mathrm{X}$, peaked at 3.359 and $3.363 \mathrm{eV}$ for APMOCVD and $\mathrm{CBD} \mathrm{ZnO}$ nanorods, respectively. The temperature increase causes a red energy shift of the peaks and enhancement of the free excitonic emission (FX). The FX was found to dominate after $150 \mathrm{~K}$ for both samples. It was observed that while APMOCVD ZnO nanorods possess a constant low signal of visible deep level emission with temperature, the $\mathrm{ZnO}$ nanorods grown by $\mathrm{CBD}$ revealed the thermal activation of deep level emission (DLE) after $130 \mathrm{~K}$. The resulting room temperature DLE was a wide band located at $420-550 \mathrm{~nm}$. The PL properties of individual $\mathrm{ZnO}$ nanorods can be of importance for their forthcoming application in future optoelectronics and photonics.
\end{abstract}

\section{PACS keywords}

$\mathrm{ZnO}$ nanorods, APMOCVD, CBD, UV photoluminescence, DLE

\section{Introduction}

Zinc oxide is a popular semiconductor material, due to its favourable properties compared to well-developed wideband gap semiconductors like $\mathrm{GaN}$ and SiC. Despite the very early reports on $\mathrm{ZnO}$ and it even being rediscovered in 1957 [1], it is still considered to be a very promising material, which might be able to contribute significantly to such areas as transparent electronics [2], solid state lighting [3,4], gas [5] and bio sensors [6], etc. This is due to a combination of its specific semiconductor and material properties. It has a wide 
direct band gap of $3.36 \mathrm{eV}$ at room temperature, which can be modified in a wide range via alloying with $\mathrm{Cd}$ (down to $2.8 \mathrm{eV}$ ) or $\mathrm{Mg}$ (up to $4.0 \mathrm{eV}$ ) [7]. The exciton binding energy is around $60 \mathrm{meV}$ at room temperature, which is one of the highest among other optoelectronic materials $(\mathrm{GaN}$ etc.) [8]. $\mathrm{ZnO}$ is transparent to visible light - the transparency of thin films is more than $93 \%$ for light of wavelength $400 \mathrm{~nm}-800 \mathrm{~nm}$ [9]. It has easily achievable n-type conductivity and via adding the donors such as Al, In, Ga, etc. highly conductive films can be obtained (up to $1-4 \times 10-4 \mathrm{Ohm} \bullet \mathrm{cm}$ ) [10]. Significant advantages of $\mathrm{ZnO}$ include the abundance of its constituent elements in nature, its low cost, and the availability of low energy consumption technology for preparation of the material. Additionally, $\mathrm{ZnO}$ is considered being non-toxic, bio-safe and biocompatible [11].

$\mathrm{ZnO}$ has been prepared by many techniques in the form of bulk crystals, two-dimensional structures (films and layers) or one-dimensional structures (nanostructures) [12]. Among them, nanostructures are the most promising and interesting, and considered to be the building blocks for forthcoming nano-optoelectronic, nano-photonic and nano-electronic devices [13]. Nanostructures may provide several advantages in comparison to thin films or bulk crystals. First, in the case of $\mathrm{ZnO}$ heteroepitaxy on a different substrate, the strain relieve may be expected in nanostructures, thus reducing the influence of lattice mismatch; second, possible quantum confinement may be observed in nanosized $\mathrm{ZnO}$ objects, which may enhance radiative recombination; third, from nanostructures of certain morphology with increased surface area and therefore, reduced reflection at the air-semiconductor interface, better light extraction may be expected. Finally, photonic crystal effects may be expected in carefully arranged periodic arrays of nanostructures [14]. All these stimulated a significant interest in $\mathrm{ZnO}$ nanostructures in the last decade.

The attractiveness of $\mathrm{ZnO}$ for optoelectronics lies in its ability to emit light in the Aultraviolet (UV) spectral range, which might enable the design of UV light emitting diodes (UV LED's). However, p-type ZnO is still a challenge and an obstacle to the realization of LED devices, based on $\mathrm{ZnO}$ homoepitaxial p-n junctions. The recombination processes in $\mathrm{ZnO}$ occur via radiative and non-radiative channels. The different types of defects in $\mathrm{ZnO}$ may serve as non-radiative recombination centres: point defects, dislocations, surface/interface states etc. Efficient light emission may be obtained via a decrease in the non-radiative contribution. This can be achieved by improved crystal quality of the material. However, even in the case of dominating radiative recombination, the light emission may occur in the UV range $(\sim 380 \mathrm{~nm})$ as well as in the visible range of spectra $(\sim 450-650 \mathrm{~nm})$. The latter is so-called defect emission and is commonly observed in $\mathrm{ZnO}$ independently of growth technique or substrate temperature. The possible origin of visible emission is deep level defects: oxygen vacancies, zinc interstitials or their combination [15]. Despite concerted efforts, the origin of defect emission in $\mathrm{ZnO}$ is still under debate.

Photoluminescence (PL) is a powerful tool for probing the light emission properties of semiconductors. Particularly, temperature dependent PL studies can give comprehensive information about the nature of the light emission and reveal the fundamental material properties. Moreover, micro-photoluminescence enables study of separate low dimensional objects. In this paper we compare the photoluminescence properties of individual $\mathrm{ZnO}$ 
nanostructures (nanorods), prepared by two different techniques - atmospheric pressure chemical vapour deposition (APMOCVD) and chemical bath deposition (CBD).

\section{Experimental}

The first type of $\mathrm{ZnO}$ nanostructure was prepared by APMOCVD [16] via decomposition of a solid state single source precursor [17]. A special growth approach, based on selective homoepitaxial growth [18] was applied. The substrate temperature was as high as $500{ }^{\circ} \mathrm{C}$. Details of the growth of $\mathrm{ZnO}$ nanostructures by APMOCVD can be found elsewhere [16]. The second type of $\mathrm{ZnO}$ nanostructure was grown by CBD using zinc nitrate hexahydrate and ammonium hydroxide. The substrate temperature was as low as $80{ }^{\circ} \mathrm{C}$, while the $\mathrm{pH}$ level of the solution was used to control the growth process. Details about the preparation of $\mathrm{ZnO}$ nanostructures are described in [19]. The silicon substrate with a natural oxide layer was chemically cleaned to remove the organic and inorganic contaminants, followed by a rinse in deionised water and drying in flowing nitrogen. The crystal quality of as-grown nanostructures was estimated by x-ray diffraction analysis (XRD) (data are not presented here). The grown nanostructures revealed single phase $\mathrm{ZnO}$. Only reflections from the (0001) plane of $\mathrm{ZnO}$ were observed in the XRD $\theta-2 \theta$ spectra. A more detailed study of the structural properties of $\mathrm{ZnO}$ nanostructures will be performed [20]. The morphology of the nanostructures was studied via scanning electron microscopy (SEM) using a Leo 1550 Gemini SEM operated at voltages ranging from 10 to $20 \mathrm{kV}$ and using a standard aperture value of $30 \mu \mathrm{m}$. The emission from the $\mathrm{ZnO}$ nanostructures was investigated by microphotoluminescence, carried out in the temperature range $8-300 \mathrm{~K}$ with a frequency doubled $\mathrm{Nd}$ :YVO laser as continuous wave excitation source, giving a wavelength $\lambda=266 \mathrm{~nm}$. The emitted luminescence was collected and mirrored into a single grating $0.45 \mathrm{~m}$ monochromator equipped with a liquid nitrogen cooled Si-CCD camera with a spectral resolution of about $0.1 \mathrm{meV}$. The excited area was around $10 \mu \mathrm{m}$ in diameter providing an excitation density of $2-400 \mathrm{~W} / \mathrm{cm}^{2}$.

\section{Results and Discussion}

The morphology of the $\mathrm{ZnO}$ nanostructures grown by APMOCVD and CBD is presented in Figure 1. The APMOCVD nanostructures are in fact hierarchical structures and were formed via deposition of a thin polycrystalline $\mathrm{ZnO}$ layer on $\mathrm{Si}$ surface; then growth of certain grains was favoured via selective homoepitaxial growth [18], resulting in short vertical nanorods 
(Fig. 1(a)). Via subsequent growth at higher supersaturation the nanorods evolved into sheaves of separate nanowires of characteristic size around $30-45 \mathrm{~nm}$ in diameter and length $2-3 \mu \mathrm{m}$ (Fig. 1(b)). The $\mathrm{ZnO}$ nanostructures grown by CBD are of nanorod shape, vertically orientated and fairly uniformly distributed over the substrate surface. The nanostructures are hexagonally faceted, reflecting the $\mathrm{ZnO}$ crystal structure and have characteristic dimensions of $\sim 300 \mathrm{~nm}$ in diameter and 1-2 $\mu \mathrm{m}$ in length. Interestingly, the nanostructures have tapered ends, which is typical for CBD growth from a basic solution [21]. The general explanation for the morphology of nanostructures, grown by both APMOCVD and CBD techniques stems from the difference in the surface free energies for the main crystallographic planes of hexagonal $\mathrm{ZnO}: \mathrm{G}_{001}=-2.8102 \mathrm{~kJ} / \mathrm{mol}, \mathrm{G}_{101}=-2.1067$ $\mathrm{kJ} / \mathrm{mol}$ and $\mathrm{G}_{100}=-2.0013 \mathrm{~kJ} / \mathrm{mol}$, respectively [22]. Due to this anisotropy, preferential growth on the plane of lowest energy occurs, providing the elongated $\mathrm{ZnO}$ structures along the c-axis.

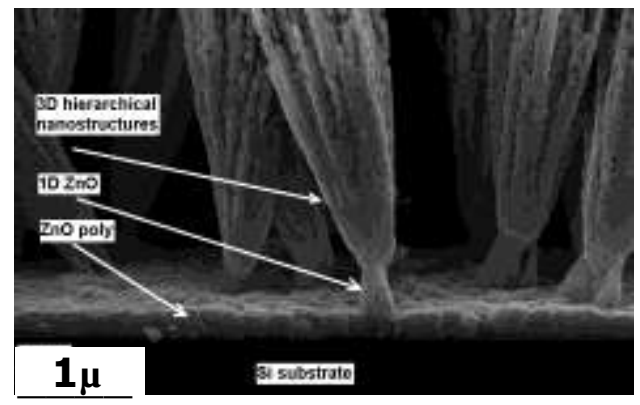

a

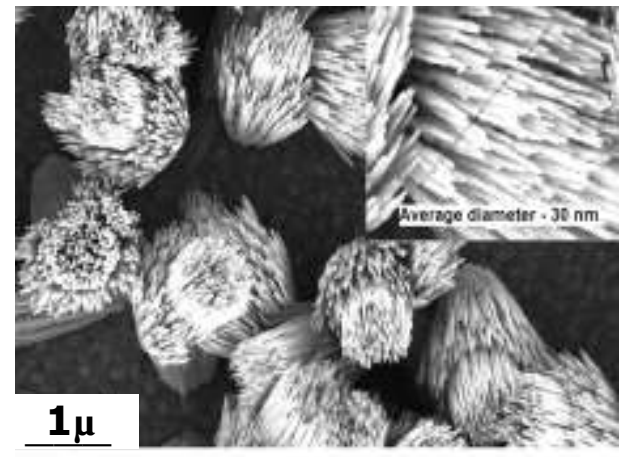

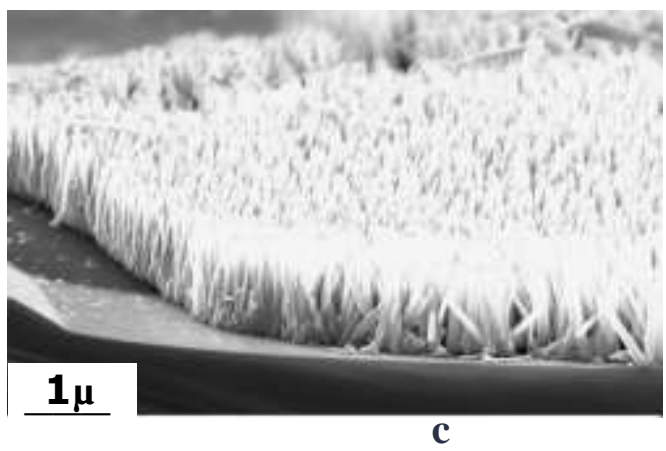

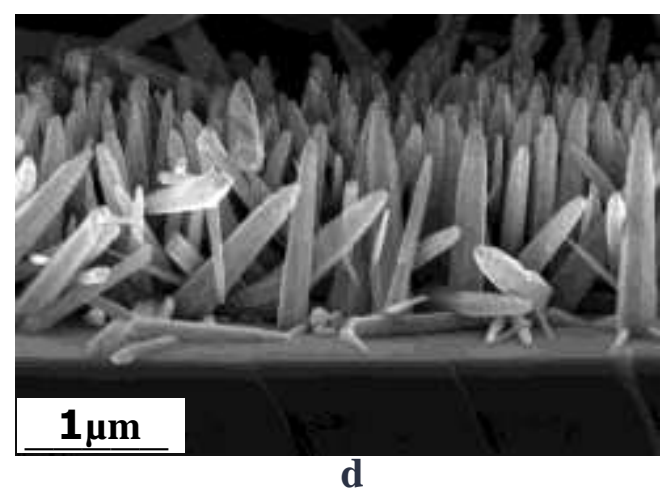

Figure 1. The microstructure morphology of the $\mathrm{ZnO}$ nanostructures, grown by APMOCVD (a,b) and CBD (c,d).

In order to avoid possible effects caused by substrate contribution or nanostructure agglomeration, the micro-PL samples were prepared by separating the nanostructures from the as-grown samples and located individually on clean Si substrate. Thus, only one 
nanostructure was probed by micro-PL. The low temperature PL spectra of $\mathrm{ZnO}$ nanostructures along with the respective SEM images of the probed nanostructures, are presented in figure 2 .
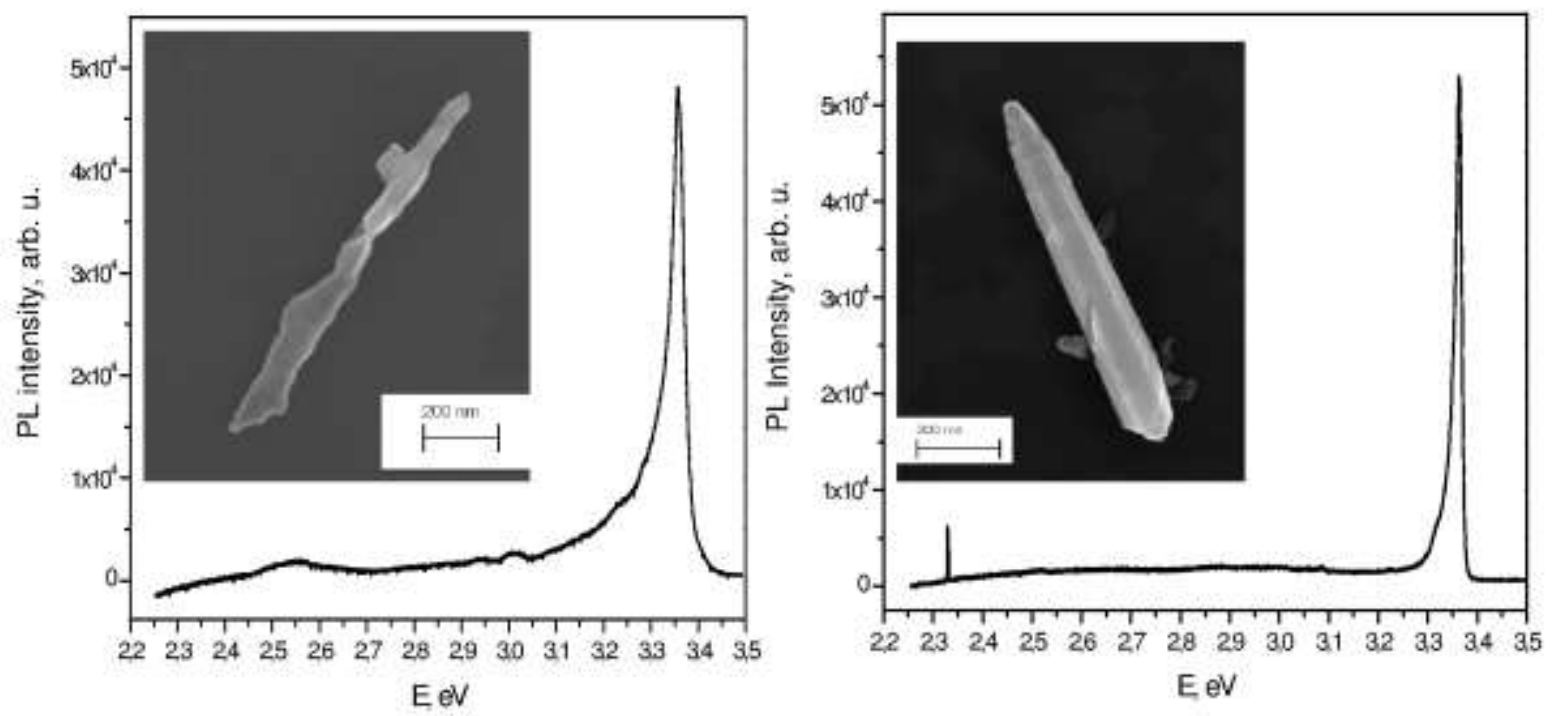

Figure 2. Low temperature $(8 \mathrm{~K}) \mathrm{PL}$ spectra of individual $\mathrm{ZnO}$ nanostructures (nanorods), grown by APMOCVD (a) and CBD (b), respectively. The inset images are SEM images of the respective nanostructures.

At low temperatures the nanostructures grown by both techniques demonstrated only one intense peak of near band edge (NBE) excitonic emission, located in the UV region and negligible emission in the visible range (i.e. DLE). The APMOCVD $\mathrm{ZnO}$ nanorod has a dominant peak at $3.359 \mathrm{eV}$ and very low DLE emission. The peak position implies that the origin is neutral donor bound excitonic $\left(\mathrm{D}^{0} \mathrm{X}\right)$ emission: the position coincides with a line at $3.3593 \mathrm{eV}$, reported for $\mathrm{Ga}$ as a donor in $\mathrm{ZnO}$ with respective localization energy $16.1 \mathrm{meV}$ [23]. The CBD sample revealed a sharp line at $3.363 \mathrm{eV}$, which is also ascribed $\mathrm{D}^{0} \mathrm{X}$ emission. The closest line reported is the so-called $\mathrm{I}_{4}$ at $3.3628 \mathrm{eV}$. According to the literature data this line is due to $\mathrm{H}$ impurities in $\mathrm{ZnO}$ with a localization energy of $13.1 \mathrm{meV}$ [24]. However, it is rather difficult to assign the peaks unambiguously, since the free excitonic emission lines $(\mathrm{FX})$ at low temperatures were not observed.

In order to confirm the peaks assignments, we performed temperature dependent PL measurements in the range $8-300 \mathrm{~K}$ (Fig. 3). A red-shift of the peaks was observed for both samples. As earlier reported, the red-shift of the exciton peaks is due to a band gap decrease and thermal dissociation of bound excitons, assuming that the exciton binding energy is 
temperature independent. It derives from both thermal expansion and exciton-phonon interaction. The observed difference in the energy peak shift for the two samples apparently means the different interaction between bound excitons and phonons. However, the reasons for that are not clear: both structures are too large for the nanoscale effect; most likely the difference observed is due to the used growth technique.

Another feature which has been observed for both samples, is the change of the dominant emission from donor bound to free excitonic with increasing temperature. The relative intensity of the peaks varies with temperature. A quenching of the intensity and a red-shift of the position of the $\mathrm{D}^{0} \mathrm{X}$ peak is obvious with the temperature increase. Moreover, at higher temperatures, a clear resolution of the $\mathrm{D}^{0} \mathrm{X}$ and $\mathrm{FX}$ peaks is possible despite spectral broadening. The $\mathrm{D}^{0} \mathrm{X}$ peak intensity decreases with temperature and finally disappears above $\sim 160 \mathrm{~K}$, being dominated by the growing FX emission. It was earlier reported that at low temperatures, the FX peak might be hidden due to dominant $\mathrm{D}^{0} \mathrm{X}$ recombination. In our case, evidence for the FX peak at low temperatures does exist, but it is barely distinguishable due to strong donor bound exciton emission. Finally, upon a further temperature increase, the FX emission becomes most dominant in the PL spectra up to room temperature. The explanation for the systematic change in the nature of the emission is that sufficient thermal energy is provided, which overwhelms the exciton binding energy (14 meV) and the dissociation of the bound exciton complex (forming free excitons) occurs [23, 24]. The emergence of the FX at higher temperature is accompanied by the appearance of its longitudinal optical (LO) phonon replicas at lower energies in the spectra.

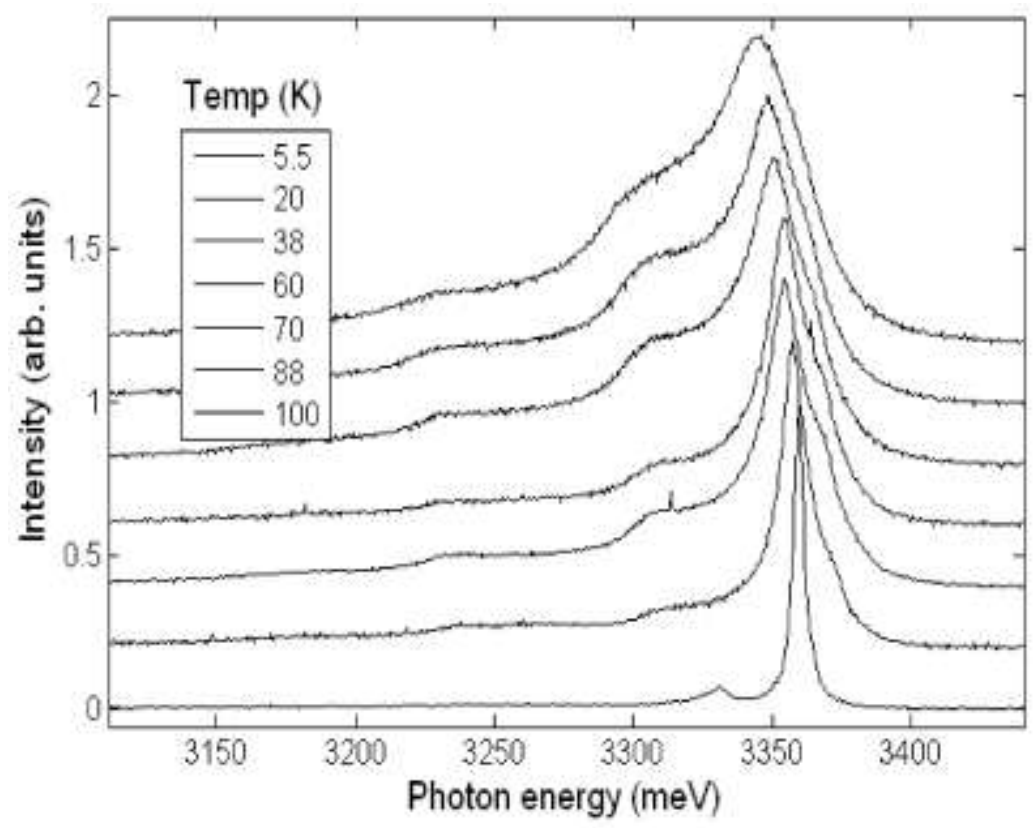


Figure 3. Temperature evolution of the PL spectra in the low temperature region $(5.5-100$ $\mathrm{K})$ the CBD sample. The spectrum measured at the lowest temperature is at the bottom and the spectrum measured at the highest temperature at the top.

The peak positions versus temperature for both samples are compared in Fig. 4. The domination of the $\mathrm{D}^{0} \mathrm{X}$ emission at low temperature and its change to $\mathrm{FX}$ emission above $150 \mathrm{~K}$ is evident for both samples.

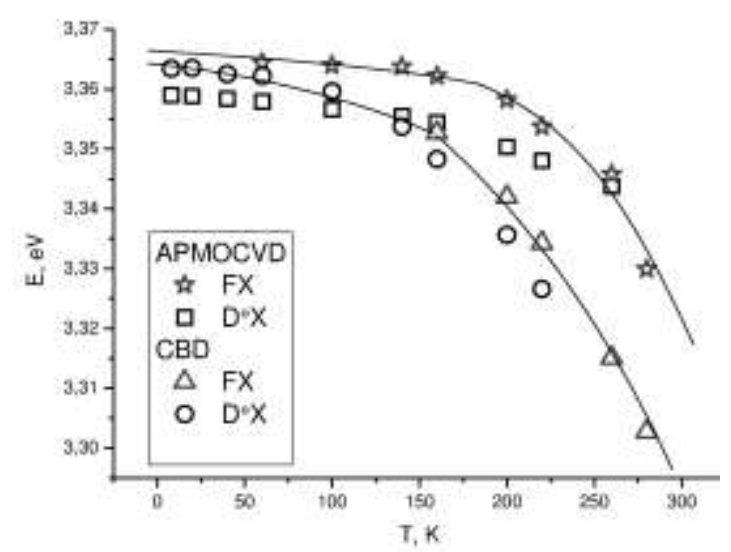

Figure 4. The energy shift for the main PL peaks ( $D^{0} \mathrm{X}$ and $\mathrm{FX}$ ) for APMOCVD and CBD grown nanorods. (The lines are guides to the eye for the FX peak position).

It was observed, that the $\mathrm{ZnO}$ nanorods grown by $\mathrm{CBD}$ demonstrated negligible visible $\mathrm{DLE}$ emission at low temperature; however, it revealed a clear threshold for the dominance of DLE at $130 \mathrm{~K}$ (Fig. 5). As can be seen, the NBE excitonic emission was found to decrease monotonically with a temperature increase. Above $130 \mathrm{~K}$ a DLE signal starts to increase almost linearly in the spectral range $420-550 \mathrm{~nm}$.

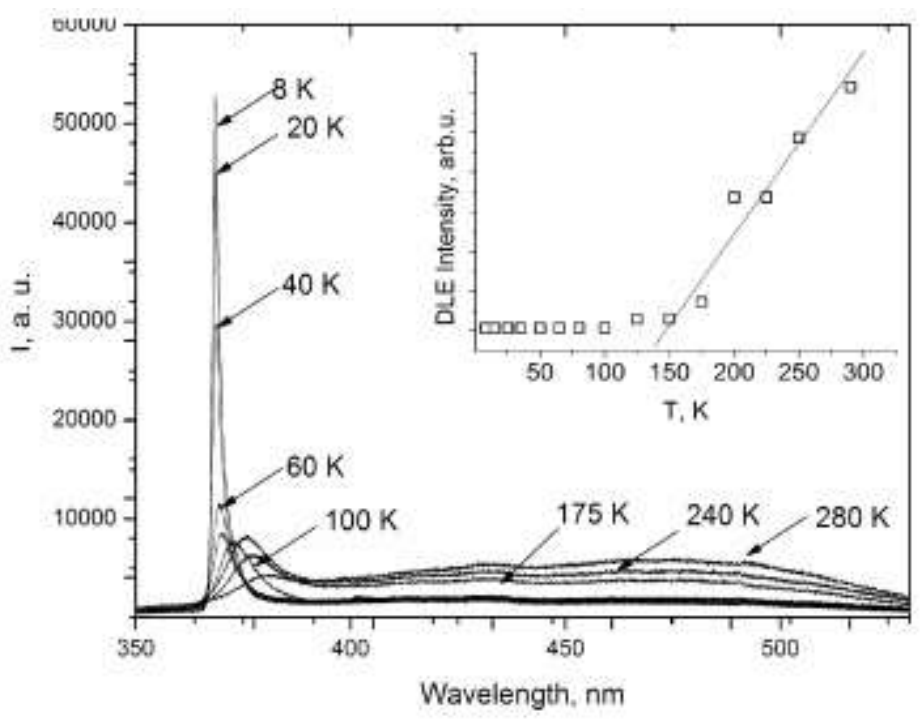


Figure 5. Temperature dependent PL spectra in the whole temperature range spectra $(8-$ $280 \mathrm{~K}$ ) of the CBD $\mathrm{ZnO}$ nanorod, showing the appearance of DLE emission with temperature increase. The insert represents the dependence of integral DLE intensity on the temperature.

It has to be mentioned that normal PL measurements of the CBD $\mathrm{ZnO}$ nanorod samples did not reveal such features, showing intense NBE emission and weak DLE. Also, nanorods produced by CBD using hexamine instead of ammonium hydroxide (in the present work) have very weak DLE at room temperature, pointing towards stoichiometric changes resulting from different $\mathrm{pH}$ of the growth solution as a likely cause of the DLE observed for the present CBD samples [25]. It should also be emphasized that no DLE activation for the APMOCVD ZnO nanorods was observed. This implies that the appearance of DLE depends on the synthesis technique. A comparison of the room temperature PL spectra of $\mathrm{ZnO}$ nanostructures are shown on figure 6. It was found that the APMOCVD $\mathrm{ZnO}$ nanostructure demonstrates NBE emission at $375 \mathrm{~nm}(3.3 \mathrm{eV})$ accompanied by weak visible luminescence at $482 \mathrm{~nm}(2.57 \mathrm{eV})$. The ratio of the integrated PL of NBE peak $\left(\mathrm{I}_{\mathrm{NBE}}\right)$ to DLE peak $\left(\mathrm{I}_{\mathrm{DLE}}\right)$ for this $\mathrm{ZnO}$ nanostructure was calculated to be around 12. In comparison the RT PL spectra of CBD ZnO demonstrates weak NBE at $380 \mathrm{~nm}(3.26 \mathrm{eV})$, followed by several overlapping peaks at $432 \mathrm{~nm}\left(2.85 \mathrm{eV}\right.$,) $466 \mathrm{~nm}(2.67 \mathrm{eV})$ and $476 \mathrm{~nm}(2.6 \mathrm{eV})$. The ratio $\mathrm{I}_{\mathrm{NBE}} / \mathrm{I}_{\mathrm{DLE}}$ for $\mathrm{CBD} \mathrm{ZnO}$ at $\mathrm{RT}$ was $\sim 0.08$. However, it has to be noticed that the overall emission of this structure is high, providing strong visible luminescence in the range $375-550 \mathrm{~nm}$. This may be interesting for the design of full-colour LEDs.
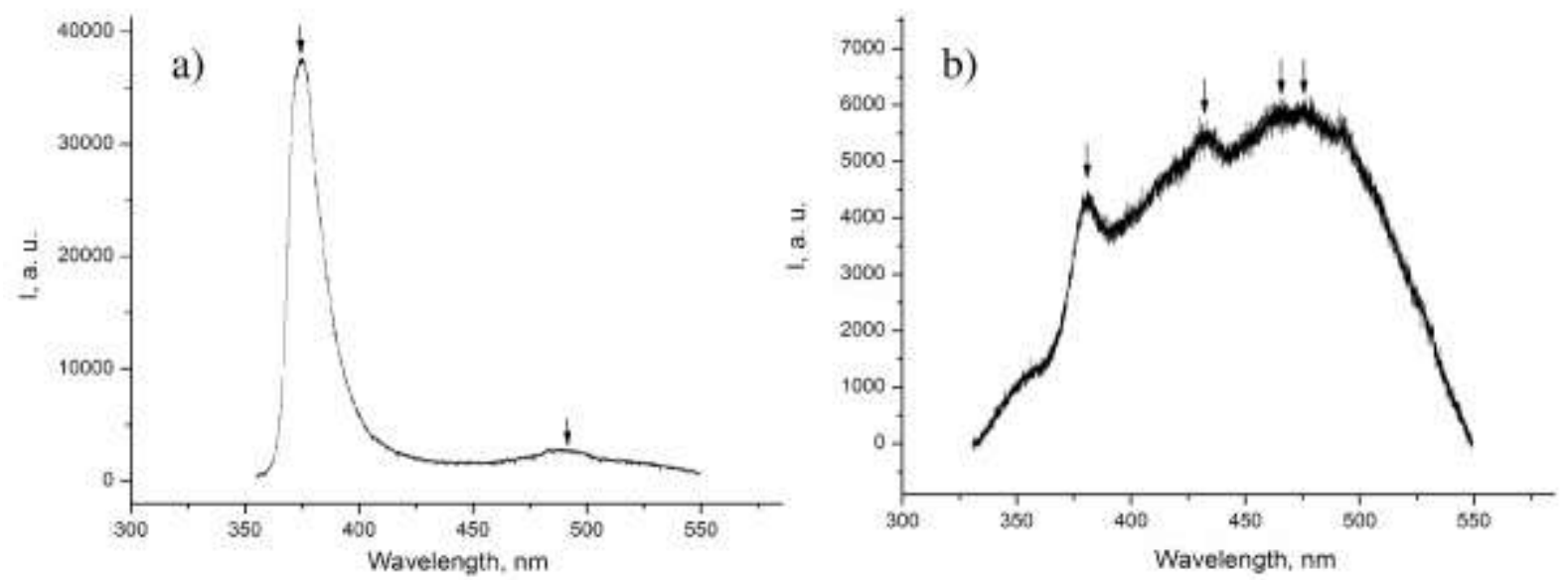

Figure 6. The room temperature PL spectra of $\mathrm{ZnO}$ nanostructures: a) $\mathrm{ZnO}$ nanostructures grown by APMOCVD possesses intense peak of NBE emission at $375 \mathrm{~nm}$ and negligible 
band of DLE emission (490 nm); b) CBD grown $\mathrm{ZnO}$ nanostructures reveal weak NBE emission at $380 \mathrm{~nm}$, followed by intense multiple bands of DLE at $432-476 \mathrm{~nm}$.

\section{Conclusions}

The luminescence features of individual $\mathrm{ZnO}$ nanostructures, prepared by APMOCVD and $\mathrm{CBD}$, have been investigated. It was observed that the low temperature PL spectra of both samples are dominated by neutral donor bound exciton emission. The visible defect emission at low temperatures is negligible for both samples. Upon a temperature increase similar red energy shifts of the main peaks was observed, but different temperature dynamics were measured for the two samples. This may be due to differences in size of the probed nanorods and therefore enhanced exciton-phonon interaction contributions, etc. The donor bound exciton emission, dominating at low temperatures, tends to be replaced by free excitonic emission in the temperature range $60-140 \mathrm{~K}$. The free excitonic emission is observed above $140 \mathrm{~K}$ (up to room temperature) for both samples. The CBD $\mathrm{ZnO}$ sample revealed the activation of defect luminescence above $130 \mathrm{~K}$. The DLE peak at room temperature consisted of several overlapping peaks, located at $420-525 \mathrm{~nm}$. The studied features of the individual nanorods are important in terms of their further application as building blocks for nano-optoelectronics, nano-photonics and nano-electronics.

\section{Acknowledgements}

Swedish Research Link (SRL-VR) 2009-6427 “ZnO Nano Structures for Energy Saving Light Emitters" (2010 - 2012) is acknowledged for the support. This work was also supported through the research chairs initiative of the SA Department of Science and Technology and the SA National Research Foundation. The NMMU is gratefully acknowledged for financial assistance.

\section{References}

[1] Harvey E. Brown, Zinc oxide Rediscovered, The New Jersey Zinc Company, New York, N. Y. 1957 
[2] V. Khranovskyy, U. Grossner, V. Lazorenko, G. Lashkarev, B.G. Svensson, R. Yakimova, Conductivity increase of $\mathrm{ZnO}: \mathrm{Ga}$ films by rapid thermal annealing // Superlattices and Microstructures 42 (2007) 379-386

[3] V. Khranovskyy, G. R. Yazdi, G. Lashkarev, A. Ulyashin and R. Yakimova, Investigation of $\mathrm{ZnO}$ as a perspective material for photonics // Physica Status Solidi A 205 (2008) 144-149.

[4] V. Khranovskyy, I. Tsiaoussis, G. R. Yazdi, L. Hultman and R. Yakimova, Heteroepitaxial $\mathrm{ZnO}$ nanohexagons on p-type SiC //Journal of Crystal Growth, 312 (2010) $327-332$.

[5] V. Khranovskyy, J. Eriksson, A. Lloyd-Spetz, L. Hultman and Rositza Yakimova, Effect of oxygen exposure on the electrical conductivity and gas sensitivity of nanostructured ZnO films // Thin Solid Films 517 (2009) 2073-2078

[6] L. Selegard, V. Khranovskyy, F. Söderlind, C. Vahlberg, M. Ahren, P.-O. Käll, R. Yakimova and K. Uvdal, Biotinylation of $\mathrm{ZnO}$ nanoparticles and thin films: a two-step surface functionalization study, ACS Appl. Materials and Interfaces, 2 (2010) 21282135

[7] M. Willander, O. Nur, Q. X. Zhao, L. L. Yang, M. Lorenz,B. Q. Cao, J. Z. Perez, C. Czekalla, G. Zimmermann, M. Grundmann, A. Bakin, A. Behrends, M. Al-Suleiman, A. El-Shaer, A. Che Mofor, B. Postels, A.Waag, N. Boukos, A. Travlos, H. S. Kwack, J. Guinard and D. Le Si Dang, “Zinc oxide nanorod based photonic devices: recent progress in growth, light emitting diodes and lasers", Nanotechnology 20 (2009) 332001

[8] Ü. Özgür, Ya. I. Alivov, C. Liu, A. Teke, M. A. Reshchikov, S. Doğan, V. Avrutin, S.J. Cho, and H. Morkoç, “A comprehensive review of $\mathrm{ZnO}$ materials and devices”, J. Appl. Phys. 98 (2005) 041301

[9] V. Khranovskyy, U. Grossner, V. Lazorenko, G. Lashkarev, B.G. Svensson, R. Yakimova, PEMOCVD of $\mathrm{ZnO}$ thin films, doped by $\mathrm{Ga}$ and some of their properties // Superlattices and Microstructures 39 (2007) 275-281 
[10] V. Khranovskyy, U. Grossner, V. Lazorenko, G. Lashkarev, B.G. Svensson, R. Yakimova, Conductivity increase of $\mathrm{ZnO}: \mathrm{Ga}$ films by rapid thermal annealing // Superlattices and Microstructures 42 (2007) 379-386.

[11] C. Klingshirn, J. Fallert, H. Zhou, J. Sartor, C. Thiele, F. Maier-Flaig, D. Schneider, and $\mathrm{H}$. Kalt, "65 years of $\mathrm{ZnO}$ research - old and very recent results", Phys. Status Solidi B 247 (2010) 1-24

[12] B. Djurisic, A. M. C. Ng, X. Y. Chen, "ZnO nanostructures for optoelectronics: Material properties and device applications", Progress in Quantum Electronics 34 (2010) 191-259

[13] Z. L, Wang, ZnO nanowire and nanobelt platform for nanotechnology, Materials Science and Engineering: R: Reports 64 (2009) 33-71

[14] B. Q. Cao, M. Lorenz, A. Rahm, H. von Wenckstern, C. Czekalla, J. Lenzner, G. Benndorf, and M. Grundmann, Nanotechnology 18 (2007) 455707

[15] K. Vanheusden C. H. Seager, W. L. Warren, D. R. Tallant, J. A. Voigt, "Correlation between photoluminescence and oxygen vacancies in $\mathrm{ZnO}$ phosphors", Appl. Phys. Lett. 68, 403 (1996); F. Leiter, H. Zhou, F. Henecker, A. Hofstaetter, D. M. Hoffman, B. K. Meyer, "Magnetic resonance experiments on the green emission in undoped $\mathrm{ZnO}$ crystals", Physica B 908, 308 (2001); D.C. Look, J. W. Hemsky, and J. R. Sizelove, “Residual Native Shallow Donor in ZnO”, Phys. Rev. Lett. 82, (1999) 2552

[16] V. Khranovskyy, I. Tsiaoussis, L. A. Larsson, P. O. Holtz and Rositza Yakimova, Nanointegration of ZnO with Si and SiC // Physica B 404 (2009) 4359 - 4363. V. Khranovskyy, A. Ulyashin, G. Lashkarev, B.G. Svensson, R. Yakimova, Morphology, electrical and optical properties of undoped $\mathrm{ZnO}$ layers deposited on silicon substrates by PEMOCVD // Thin Solid Films 516 (2008) 1396-1400

[17] V. Khranovskyy, R. Minikayev, S. Trushkin, G. Lashkarev, V.1 Lazorenko, U. Grossner, W. Paszkowicz, A.j Suchocki, B. G. Svensson and Rositza Yakimova, Improvement of $\mathrm{ZnO}$ thin film properties by application of $\mathrm{ZnO}$ buffer layers // Journal of Crystal Growth 308 (2007) 93-98 
[18] V. Khranovskyy, I. Tsiaoussis, L. Hultman and R. Yakimova, Selective homoepitaxial growth and luminescent properties of ZnO Nanopillars, Nanotechnology 22 (2011) 185603

[19] Z. N. Urgessa, E. J. Olivier, J. H. Neethling, O. S. Oluwafemi, J. R. Botha, Effect of precursor concentration on the growth of $\mathrm{ZnO}$ nanorods arrays on pre-treated substrate, physica b (submitted May 2011)

[20] V. Khranovskyy, L. Hultman and R. Yakimova, Engineering the crystal growth: ZnO nanostructures morphology evolution - paper submitted to Physica B (this issue)

[21] S. Baruah and J. Dutta, pH-dependent growth of zinc oxide nanorods // J. Crystal Growth 311 (2009) 2549-2554

[22] N. Fujimura, T. Nishihara, S. Goto, J. Xu, T. Ito, Control of preferred orientation for ZnOx films: control of self-texture // J. Cryst. Growth 130 (1993) 269-279

[23] B. K. Meyer, H. Alves, D. M. Hofmann, W. Kriegseis, D. Forster, F. Bertram, J. Christen, A. Hoffmann, M. Straßburg, M. Dworzak, U. Haboeck and A. V. Rodina, Bound exciton and donor-acceptor pair recombinations in $\mathrm{ZnO} / /$ Phys. Stat. Sol. (b) 241 (2004) 231- 260

[24] B. K. Meyer, J. Sann, D. M. Hofmann, C. Neumann and A. Zeuner, Shallow donors and acceptors in $\mathrm{ZnO} / /$ Semicond. Sci. Technol.20 (2005) S62.

[25] Z.N. Urgessa, OS Oluwafemi, JR Botha, Photoluminescence study of aligned ZnO nanorods grown using Chemical Bath Deposition, physica b (submitted May 2011) 


\section{Figure captions}

Figure 1. The microstructure morphology of the $\mathrm{ZnO}$ nanostructures, grown by APMOCVD $(a, b)$ and CBD (c,d).

Figure 2. Low temperature ( $8 \mathrm{~K}) \mathrm{PL}$ spectra of individual $\mathrm{ZnO}$ nanostructures (nanorods), grown by APMOCVD (a) and CBD (b), respectively. The inset images are SEM images of the respective nanostructures.

Figure 3. Temperature evolution of the PL spectra in the low temperature region $(5.5-100$ $\mathrm{K})$ the CBD sample. The spectrum measured at the lowest temperature is at the bottom and the spectrum measured at the highest temperature at the top.

Figure 4. The energy shift for the main PL peaks (DOX and FX) for APMOCVD and CBD grown nanorods. (The lines are guides to the eye for the FX peak position).

Figure 5. Temperature dependent PL spectra in the whole temperature range spectra $(8-$ $280 \mathrm{~K}$ ) of the CBD $\mathrm{ZnO}$ nanorod, showing the appearance of DLE emission with temperature increase. The insert represents the dependence of integral DLE intensity on the temperature.

Figure 6. The room temperature PL spectra of $\mathrm{ZnO}$ nanostructures: a) $\mathrm{ZnO}$ nanostructures grown by APMOCVD possesses intense peak of NBE emission at $375 \mathrm{~nm}$ and negligible band of DLE emission (490 nm); b) CBD grown $\mathrm{ZnO}$ nanostructures reveal weak NBE emission at $380 \mathrm{~nm}$, followed by intense multiple bands of DLE at $432-476 \mathrm{~nm}$. 